\title{
A língua italiana e a escola como espaços SIMBÓLICOS DE DISPUTA NO INÍ́CIO DO SÉCULO XX: IMPLICAÇÕES POLÍTICAS, SOCIAIS E CULTURAIS
}

\author{
Deise Cristina de Lima Piganço \\ Maria Inès Carvalho Correia
}

\begin{abstract}
RESUMO: Este artigo tem como objetivo refletir, sob o viés histórico, sobre a presença ausente da(s) língua(s) e cultura(s) italiana(s) no currículo de ensino médio em Curitiba, mais especificamente no Colégio Estadual do Paraná no início do século XX. Como tratar de cultura e linguagem é tratar do sujeito sociológico e historicamente situado, sempre em movimento, na relação com o outro, destacamos nessa reflexão três pontos que acreditamos estejam relacionados com a questão da língua, a saber: a) a divergência entre os sujeitos imigrantes italianos social e historicamente situados; b) a ideologia do branqueamento do Brasil por parte da elite brasileira; e c) a ausência de tradição da língua italiana falada standard nesse período. Para essa reflexão, tomam-se como base as ideias do Círculo de Bakhtin sobre linguagem indissociada de sujeito híbrido e a noção de diferença cultural que ocorre na enunciação, conforme definida por Bhabha (2013).

PALAVRAS-CHAVE: língua italiana; discurso e educação; ideologia; história do Brasil
\end{abstract}

ABSTRACT: Questo articolo ha come scopo riflettere, dal punto di vista storico, sulla presenza assente della/e línguale e cultura/e italianale nel programma di insegnamento della scuola media superiore a Curitiba, più specificamente nel

\footnotetext{
* Universidade Federal do Paraná, Curitiba (Brasil) - deisepicanco@gmail.com / inescarvalho3@gmail.com
} 
Colegio Estadual do Paraná all'inizio del XX secolo. Poiché affrontare l'argomento cultura e linguaggio è affrontare anche il soggetto situato sociologicamente e storicamente, sempre in movimento, in rapporto con l'altro, distinguiamo in questa riflessione tre punti che consideriamo intrecciati con la questione della lingua, vale a dire: a) la divergenza fra i soggetti immigrati italiani socialmente e storicamente situati; b) l'ideologia dello "sbiancamento" del Brasile da parte dell'élite brasiliana; e c) la mancata tradizione di una lingua italiana parlata standard. L'approccio teorico utilizzato in questa riflessione è basato sulle idee del Circolo di Bachtin relative al linguaggio indissociato dal soggetto ibrido e alla nozione di differenza culturale che si mostra nell'enunciazione, così come definita da Bhabha (2013).

PAROLE CHIAVE: lingua italiana; discorso ed educazione; ideologia; storia del Brasile

ABSTRACT: This article aims to reflect, from a historical perspective, on the absent presence of the Italian language(s) and culture(s) in the high school curriculum in Curitiba, more specifically at the State College of Parana at the beginning of the 20th century. As to deal with culture and language is to deal with the sociological and historically situated subject, always in movement, in his relation to the Other, we highlight in this reflection three points that we believe are related to the question of language, namely: a) the divergence between the socially and historically situated Italian immigrant subjects; b) the Brazilian elite's ideology of Brazil's racial whitening; c) the lack of a standard spoken Italian tradition in this period. Our reflection is based on the ideas of Bakhtin>s Circle that language is indissoluble from the hybrid subject and on the notion of cultural difference that occurs in enunciation, as defined by Bhabha (2013).

KEYWORDS: Italian Language; discourse and education; ideology; History of Brazil 


\section{Impactos das políticas de branqueamento e imigração no Brasil}

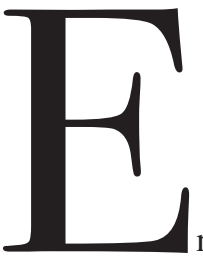

no Brasil, nos séculos XIX e XX, nem sempre as Línguas Estrangeiras foram negligenciadas na escola. O processo de retirada das línguas e das disciplinas conhecidas como humanidades ocorreu no Brasil ao mesmo tempo em que se intensificou o processo de nacionalização que teve início no final dos anos 20, alcançando seu apogeu apenas no final da década de 30. Entretanto, ainda "durante a década de 30, a língua estrangeira ocupou um espaço importante ao lado do idioma nacional. Faziam parte do currículo o francês, o inglês e o alemão" (PICANÇO, 2003, p.31).

O idioma italiano esteve presente na escola secundária por apenas dois anos (de 1929 a 1931), como disciplina curricular obrigatória, juntamente com as demais Línguas Estrangeiras (doravante LE), conforme as orientações do Colégio Dom Pedro II, que na época era responsável por editar as normas de funcionamento das escolas secundárias públicas no país, 
como o Ginásio Paranaense. Essa informação instigou o questionamento sobre as possíveis causas dessa presença ausente do italiano no currículo escolar, como Língua Estrangeira, contrastando com o grande número de imigrantes italianos que viviam no Brasil e, no nosso caso, mais precisamente no Paraná.

Essa presença ausente, que está prevista, mas não se efetiva, foi ainda mais sentida nos últimos anos, com a possibilidade de escolha da língua estrangeira pela comunidade escolar garantida pela LDB de 1996, e com a mudança no papel formativo da LE como disciplina escolar. Segundo os Parâmetros Nacionais de Ensino de Língua Estrangeira (PCNs/ELE, 1998, p.23): "a convivência entre comunidades locais e imigrantes ou indígenas pode ser um critério para a inclusão de determinada língua no currículo escolar. Justifica-se pelas relações envolvidas nessa convivência: as relações culturais, afetivas e de parentesco". O idioma italiano poderia ser facilmente enquadrado nesse quesito no Paraná, em especial em Curitiba.

Historicamente, nas décadas de 1920 e 1930, a escola esteve no centro das preocupações do poder político do Brasil (SCHWARTZMAN, 2000 [1984], p.91), muito mais por aquilo que representava do que pelo investimento que se fazia. Um dos problemas mais emblemáticos e marcantes daquele momento foi a tentativa de se criar uma consciência nacional única, e a escola seria vista como espaço ideal para forjar a identidade nacional nos jovens. É pertinente destacar que essas ideias nacionalistas eram semelhantes às disseminadas na Itália, com o regime fascista, e na Alemanha, com o regime nazista. Como bem recorda Bakhtin/Voloshinov (2009, p.48), "a classe dominante tende a conferir ao signo ideológico um caráter intangível e acima das diferenças de classe, a fim de abafar ou de ocultar a luta dos índices sociais de valor que aí se trava, a fim de tornar o signo monovalente".

Dentre as ações usadas na construção da identidade nacional, estava a imposição da língua portuguesa como língua oficial. Com isso houve uma série de perseguições, intensificadas na década de 1940, aos falantes de outras línguas em território nacional. Essas ações atingiram colônias de imigrantes alemães, italianos e japoneses com maior incidência. Alguns imigrantes chegaram a ser presos por se expressarem na língua com a qual eles se identificavam "afetivamente, língua que fundou sua subjetividade" (CORACINI, 2007, p.122). De acordo com Schwartzman, alguns documentos afirmavam que "mesmo na raça latina e assimilável como é a italiana, nota-se uma grande tendência para conservar a língua e os costumes, quando formando regulares aglomerações; nas colônias alemãs então, a propensão conservadora é ainda muito maior; agravada pela diferença de língua e dos costumes" (2000 [1984], p.91).

Entretanto, o desejo de que o imigrante europeu assumisse como sua a Pátria que o havia acolhido, já estava implícito no início do processo da imigração, no final do século XIX, pela crença disseminada entre a elite brasileira de que ele poderia "salvar o Brasil" (SCHWARTZMAN, 2000 [1984], p.91) da ruína racial e das amarras do provincianismo.

O processo da imigração de europeus para o Brasil aconteceu, com grandes números, entre o final de 1800 e o início de 1900 , em meio às vozes majoritariamente difundidas entre a elite brasileira de que se deveria acabar com a escravidão, substituindo a mão de obra 
escrava pela mão de obra europeia. Essa tese estava vinculada a duas ideologias centrais: o processo de modernização e o branqueamento do país. Assim, o discurso proeminente entre vários intelectuais da época, segundo Franco, era que "o Estado devia incentivar não apenas a imigração de colonos europeus, mas devia também introduzir leis que estimulassem os casamentos entre mestiços e brancos [...]"(1821, apud HOFBAUER, 2003, p.80).

O ideário que defendia o branqueamento do Brasil, segundo Hofbauer, perdurou até meados dos anos 1950, baseado na ideia de que, contrariamente aos escravos, "a mão de obra branca seria mais produtiva que a mão de obra negra. [...] Branco já não simbolizava mais exclusivamente valores morais-religiosos nem só o status de liberdade: agora a cor branca seria também projetada na ideia do progresso" (HOFBAUER, 2003, p.80). Entretanto, é relevante observar que, como herdeiros da tradição greco-cristã-burguesa (CAMBI, 2008) e dos ideais franceses de civilização, muitos imigrantes se sentiam superiores, não aceitando, consequentemente, a condição de miscigenação estabelecida pela política de imigração da elite brasileira.

O maior equívoco dos responsáveis pelo processo de imigração era ver, por exemplo, todos os italianos como um bloco unívoco, com língua e valores semelhantes. Entretanto, mesmo advindos do mesmo país, sabemos que eles eram constituídos por experiências culturais diversas, ou seja, por diferenças culturais que culminavam em relações divergentes. Dentre essas diferenças destacamos: a história, a língua, a religião. E como nos alerta Bhabha, "apesar de histórias comuns [...] o intercâmbio de valores, significados e propriedades pode nem sempre ser colaborativo e dialógico, podendo ser profundamente oposto, conflituoso e até antagônico" (BHABHA, 2013, p.20). Não basta, portanto, para Bhabha, a diversidade cultural, pois é preciso apontar também a diferença, aquilo que não é, ou seja, que não pode ser reconhecido como pertencente ao grupo identitário. A necessidade de reconhecer a diferença é que permite a reconfiguração das identidades dos sujeitos por meio da hibridização cultural. Por isso, não é contra a diversidade que a hegemonia investe suas ações, mas contra o processo de hibridização cultural. Considerando que a Itália era herdeira, segundo Ponce (1983, p. 114), de uma tradição humanista dividida - de um lado os humanistas burgueses de esquerda (mais precisamente florentinos), ateus; e, de outro, os humanistas de direita (ligados à igreja Católica) - não havia modo de essas convivências conflituosas não ocorrerem também aqui no Brasil. O reflexo dessas lutas internas pode ser percebido na questão da língua: mesmo após a unificação política, não havia consenso na sociedade italiana sobre qual língua falada utilizar. Por um lado, havia a discussão sobre a necessidade de uma língua escrita única para se fazer literatura, usando como modelo o Florentino, por ser o dialeto de maior prestígio entre escritores, poetas, cientistas, filólogos e pela importância das obras que o haviam utilizado desde o século XIV. Por outro lado, no entanto, no âmbito da língua falada, os italianos usavam apenas a língua do seu lugar de origem, ou seja, da comunidade local na qual viviam (MARONGIU, 2000, p.2425), com enormes diferenças entre um lugar e outro. 
É pertinente notar que o número de colonos italianos vindos para a região de Curitiba foi bem superior ao número de artesãos, intelectuais e comerciantes. Essa distinção fazia parte da estratégia dos responsáveis, naquele momento, pela imigração no país. Segundo Seyferth, havia entre os imigrantistas do século XIX a ideia do bom imigrante, em detrimento do negro livre e do nativo (denominados bugre), por isso,

o esforço classificatório dirigiu-se para a nomeação das virtudes e defeitos de cada nacionalidade europeia, em função do interesse maior: o imigrante agricultor. [...] $\mathrm{Na}$ classificação imperavam os atributos usualmente associados ao campesinato, incluindo a adjetivação da submissão: o bom colono deve ter amor ao trabalho e à família e respeito às autoridades, além de ser sóbrio, perseverante, morigerado, resignado, habilidoso, etc. Alemães e italianos são as nacionalidades mais frequentemente situadas no topo da hierarquia dos desejáveis ‘bons agricultores' (2002, p.120).

A maioria dos colonos italianos era advinda das regiões mais ao Norte da Itália, critério também exigido por esses imigrantistas. Em sua maioria, vinham do Vêneto, mas também do Trentino Alto-Adige e mantinham principalmente suas línguas locais, os denominados dialetos, sendo que aquilo que os unia era a religião. Contrastavam com os comerciantes que, em sua maioria, apresentavam-se como ateus. Vale notar que, diferentemente dos imigrantes italianos, a questão linguística era o que unificava os grupos de imigrantes alemães, pois "a tradição do pensamento alemão [estava em] estabelecer estreitas ligações da história do povo com a língua" (CAMPOS, 2006, p. 27-28), por isso, os imigrantes eram apegados ao seu idioma.

A diversidade social, política, econômica, religiosa e educacional, segundo Vechia (2002), determinou que os imigrantes do centro urbano e os das colônias seguissem ritmos distintos, especialmente no que tange à sua organização social e cultural. Portanto, nas colônias, a força centralizadora era a igreja católica: "a crença religiosa era sustentada por princípios dogmáticos, rígidas normas éticas"; o Padre frequentemente era o animador, protetor, conselheiro que respondia pela comunidade, revestido de toda autoridade e de um "poder simbólico [...] exercido com a cumplicidade" (BOURDIEU, 2010, p.08) daquele grupo. Um exemplo típico dessa tradição é o Padre Piero Colbacchini, um dos sacerdotes de maior destaque na época, que esteve junto aos imigrantes colonos no Paraná. Aproveitando sua experiência no Brasil, e preocupado com o futuro espiritual dos seus prediletos colonos do Paraná (COLBACCHINI, 1896, p.6), escreveu um livro, chamado "Guia Espiritual do imigrante italiano de 1896", no qual recomenda seus fieis a seguirem retamente os preceitos da Igreja, rejeitando as modificações já presentes, os hibridismos, os deslocamentos que estavam ocorrendo nas relações sociais entre colonos e nativos.

No seu discurso, o Padre ressaltava também a italianità e a língua: 


\begin{abstract}
Assim como para a maior parte dos emigrantes italianos, essas circunstâncias melhores encontram-se na América, assim será a América a sua pátria de adoção melhor do que a Europa, e assim será o Brasil, a Argentina e qualquer outro estado do sul e do norte deste imenso continente, a pátria daqueles que na Itália faltam, e talvez ainda faltariam os meios necessários à vida. [...] Falem da Itália aos seus filhos; que eles saibam que nas suas veias corre o sangue italiano nobre e generoso pelas grandes obras da fé, das ciências e das artes. Conservem entre vocês a sua bela língua, que agrada tanto também aos estrangeiros, e retorna a eles como um canto de poesia; continuem em seus bons costumes italianos; na sua jovialidade, nas suas festas religiosas que caracterizam aquela fé que em larga escala vocês atingiram em profundidade, e que podem infundir nos outros com os seus bons exemplos. (COLBACCHINI, 1896, p.87-88)
\end{abstract}

Há vários elementos nesse discurso que merecem destaque, como, por exemplo, a ideia de Itália que os imigrantes deveriam guardar na memória e passarem aos descendentes. Entretanto, destacam-se outros pontos pertinentes para a reflexão: a primeira é o comum acordo entre as ideias do Padre e alguns membros da elite brasileira, mesmo que por razões distintas, de que os imigrantes italianos eram superiores aos negros e nativos brasileiros; o segundo aspecto diz respeito às questões da italianità e da língua italiana que discutiremos a seguir.

\title{
2. A língua italiana LE no currículo da escola pública secundária: Colégio Estadual do Paraná (CEP)
}

Para muitos colonos, a religião e a localidade de onde provinham eram seus grandes valores, de modo que eles ignoravam a Itália como país politicamente unificado. Nos centros urbanos, habitados por comerciantes, artesãos, profissionais liberais, na sua maioria com concepções político-sociais e religiosas distintas daquelas dos colonos, circulava outra visão de Itália: moderna, unificada, pronta para ocupar seu espaço no Brasil. E a escola, em especial, era o local onde aflorava a diferença entre esses imigrantes.

No final do século XIX, alguns comerciantes, intelectuais e artesãos, reivindicavam uma escola em língua italiana laica, sem a interferência da igreja, conforme ao novo estado laico italiano, em consonância com a ideia de nacionalização da língua italiana na Itália. Também no Brasil essas ideias tinham ressonância, por isso a comunidade italiana imigrante urbana fundou a Sociedade Garibaldi, em 1883. Segundo Vechia,

Entre os imigrantes italianos, portanto, existiam diferentes visões sobre a questão da identidade étnica e cultural. Para muitos intelectuais de 


\begin{abstract}
diferentes matizes políticos e/ou ideológicos, liberais, anarquistas, maçons; a identidade étnica e cultural tinha um cunho nacionalista; a italianidade deveria ser preservada pela exaltação dos valores da pátria de origem. O cultivo da língua italiana era tido como elemento de preservação dessa identidade e a escola era vista como instrumento de preservação deste elemento. Esse matiz patriótico era expresso em outras esferas. A primeira associação fundada recebeu o nome do herói da pátria - Garibaldi e o dia 20 de setembro - considerado o dia da Unificação Italiana - era sempre efusivamente comemorado (2002, p. 04).
\end{abstract}

Essa associação foi apenas uma das alternativas de difusão da italianità, através do ensino laico da língua italiana padrão no Paraná, atendendo aos apelos da nova Itália politicamente unificada. Os sentidos da expressão italianità serão disputados na enunciação, nos debates, nos jornais e nos sermões. Segundo Bhabha, a diferença cultural e ideológica se manifesta nesse embate expressivo, marcando as posições enunciativas dos sujeitos. Portanto, a língua italiana, e seu ensino, não eram sinônimos de consenso entre os imigrantes italianos, e tampouco entre membros da elite brasileira. Embora estivesse prevista no currículo da escola secundária no período de 1929 a 1931, não é possível afirmar que ela foi ensinada no Ginásio Paranaense. Além disso, a pesquisa documental mostrou que a língua italiana estava prevista como componente curricular não apenas no final da década de 20, mas também nos períodos anteriores. No Centro de Memória do Colégio Estadual do Paraná, encontrou-se um livro chamado "Livro de instruções para os exames do curso seriado e de preparatórios, bem como para os exames de admissão nos institutos de Instrução secundaria, no anno Lectivo de 1927. Rio de Janeiro”. Neste era indicada a possibilidade de os alunos estudarem a língua italiana como disciplina facultativa a partir do $4^{\circ}$ ano do curso seriado. Portanto, havia a opção de se fazer o exame de admissão para o quinto ano em língua italiana. Essa constatação permite pensar que a língua italiana padrão (italiano standard) fora realmente ensinada no Brasil, e, por esse motivo, aparece também, como opção, nesse documento a que tivemos acesso. No entanto, não é apenas nesse período que a língua italiana LE aparece entre as disciplinas de língua estrangeira. Segundo Chagas (1967), o italiano já figurava como disciplina facultativa no nível secundário desde o Império, chegando à República. No período entre 1889 e 1930 , aproximadamente, a situação da língua italiana agravou-se, saindo do currículo em 1890 e reaparecendo apenas em 1925. Encontrou-se um Livro-Ata de 1928, no qual consta que nesse período ocorrera concurso público para várias cadeiras, dentre as quais história da civilização, português, história universal e do Brasil e, também em Língua Estrangeira inglês, alemão e francês, bem como o latim (língua clássica). Tudo indica que não houve nenhum concurso para a cadeira de língua italiana LE. O Decreto no 18.564, de 15 de Janeiro de 1929, da Congregação do Collegio D. Pedro II, alterou a seriação do curso secundário (definida anteriormente pelo decreto n. 16.782-A, de 13 de janeiro de 1925), inserindo o ensino da língua italiana LE no 
currículo, no sexto ano do ensino secundário. Sendo assim, se ocorreu o ensino da língua italiana LE no CEP, essa atividade contou com algum professor temporário, mas não concursado. Infelizmente, até o momento, não se encontram indícios conclusivos no Centro de Memórias do CEP, sobre o ensino da língua italiana LE.

\section{Considerações finais}

Mostrou-se, nesta pesquisa, que o italiano como LE manteve uma presença ausente no currículo escolar do Ensino Médio em Curitiba, tanto como disciplina obrigatória, quanto como disciplina facultativa. A língua consta nos documentos, mas não há indícios de sua efetivação em sala de aula, nem há notícias da forma como teria sido ensinada. Mesmo com todo o investimento do governo italiano no Brasil, parece que o desejo de expandir a italianità não atingiu as autoridades brasileiras, para garantir concursos públicos e a importância de se inserir a língua italiana standard no currículo escolar secundário. De certo modo, esse desejo não atingiu nem mesmo os imigrantes italianos que aqui se estabeleceram.

Enfim, a situação conturbada em que vivia a Itália, os conflitos no cenário mundial, o desejo de alguns membros da elite brasileira de que os imigrantes italianos assimilassem a nova terra como sua parecem não ter sido suficientes para que fosse garantido o espaço para a língua italiana LE no currículo escolar.

Hoje, a história se repete, com a Reforma do Ensino Médio e as mudanças promovidas na LDB, aprovadas pelo congresso em 2016, se quer de novo tirar força ao plurilinguismo. Sendo assim, faz-se necessária uma grande mobilização, entre professores, pais e estudantes, para que as línguas estrangeiras voltem a cumprir seu papel formativo na educação dos jovens durante a Escola Básica.

\section{Referèncias}

BAKHTIN, M.M.;VOLOSHINOV/V. N. Marxismo e filosofia da linguagem: problemas fundamentais do método sociológico na ciência da linguagem. São Paulo, HUCITEC, 2009.

BHABHA. H.K. O Local da Cultura. Trad. M. Ávila; E.L. Lima Reis; G.R. Gonçalves. Belo Horizonte, Editora UFMG, 2013.

BOURDIEU, P. Os três estados do capital cultural. In: Nogueira, M. A.; Catani, A. Escritos de Educação. $11^{\text {a }}$ Ed. Petrópolis, Vozes, 2010, p.71-79.

CEP - Centro de Memória do Colégio Estadual do Paraná. 1927: Livro de instruções para os exames do curso seriado e de preparatórios, bem como para os exames de admissão nos institutos de Instrução secundaria, no anno Lectivo de 1927. p.12, Rio de Janeiro. 
BRASIL/MEC/SEF. Parâmetros Curriculares: terceiro e quarto ciclos do ensino fundamental: língua estrangeira, 1998. Disponível em:

$<\mathrm{http} / / /$ portal.mec.gov.br/seb/arquivos/pdf/pcn_estrangeira.pdf $>$. Acesso em: 10 de maio de 2017.

CHAGAS, R. V. C. Didática Especial de línguas Modernas. 2a ed. São Paulo, Nacional, 1967.

CAMBI, F. Intercultura: fondamenti pedagogici. Roma, Carocci Editore, 2008.

CAMPOS, C. M. A política da língua na era Vargas: proibição do falar alemão e resistência no Sul do Brasil. Campinas - SP, Ed. Unicamp, 2006.

COLBACCHINI, P. Guida Spirituale per l'immigrato italiano nella America, 1896. < file:///C:/Users/ Downloads/04_Guida\%20spirituale\%201896\%20(3).pdf>. Acesso em: 20 de agosto de 2017.

CORACINI, M. J. A celebração do outro: arquivo, memória e identidade: línguas (materna e estrangeira), plurilinguismo e tradução. Campinas - SP, Mercado de Letras, 2007.

HOFBAUER, A. O Conceito de "raça" e o ideário do "branqueamento" no século XIX - bases ideológicas do racismo brasileiro. Disponível em: <http://www.teoriaepesquisa.ufscar.br/index.php/tp/ article/viewFile/57/47>. Acesso em: 10 de maio de 2017.

MARONGIU, P. Breve storia della lingua italiana per parole. Roma, Le Monnier, 2000.

MASCHIO, E.C.F. A Escolarização dos imigrantes e seus descendentes nas colônias italianas de Curitiba, entre táticas e estratégias de italianità e brasilianità (1875-1930). Tese de Doutorado em Educação. UFPR, Curitiba, 2012. <http://www.ppge.ufpr.br/teses/D12_Elaine\%20C\%C3\%A1tia\%20 Falcade\%20Maschio.pdf>. Acesso em: 10 de maio de 2017.

PICANÇO, D.C. L. História, memória e ensino de espanhol (1942-1990): as interfaces do ensino da língua espanhola como disciplina escolar a partir da memória de professores, métodos de ensino e livros didáticos no contexto das reformas educacionais. Curitiba: UFPR, 2003.

PONCE, A. Educação e Luta de Classes. Cortez, São Paulo, 1983.

SCHWARTZMAN, S.; BOMENY, H. M. B.; COSTA, V. M. R. Tempos de Capanema: a construção da nacionalidade. Disponível em:

<http://www.schwartzman.org.br/simon/capanema/introduc.htm>. Acesso em: 20 de agosto de 2017.

SEYFERTH, G. Colonização, imigração e a questão racial no Brasil. Revista USP, São Paulo, n. 53, p. 117-149, março/maio, 2002.

VECHIA, A. Forjando identidades: a educação dos imigrantes 'italianos' em Curitiba no século XIX. In: II Congresso Brasileiro de História da Educação, 2002, Natal. Anais do Congresso Brasileiro de História da Educação. Natal: Editora Núcleo de Arte e Cultura da UFRN, 2002. v. 1. Disponível em: de 2017 $<$ http://sbhe.org.br/novo/congressos/cbhe2/pdfs/Tema6/0636.pdf>. Acesso em: 10 de setembro

Recebido em 10/09/2017 Aprovado em 20/11/2017 